\title{
A meta-analysis of the association between physical demands of unpaid domestic work and back pain among women
}

\section{Abisola Modupe Osinuga ( $\sim$ abisola-osinuga@uiowa.edu )}

University of lowa BME: The University of lowa Roy J Carver Department of Biomedical Engineering https://orcid.org/0000-0002-1418-1661

\section{Chelsea Hicks}

University of lowa: Department of Occupational and Environmental Health

\section{Segun E Ibitoye}

University of Ibadan

\section{Marin Schweizer}

university of lowa: Department of Epidemiology

\section{Nathan Fethke}

University of lowa: Department of Occupational and Environmental Health

Kelly Baker

University of lowa: Department of Occupational and Environmental Health

\section{Research article}

Keywords: Domestic work, women, physical demands, biomechanical, musculoskeletal, meta-analysis

Posted Date: December 22nd, 2020

DOl: https://doi.org/10.21203/rs.3.rs-131819/v1

License: (9) This work is licensed under a Creative Commons Attribution 4.0 International License.

Read Full License

Version of Record: A version of this preprint was published at BMC Women's Health on April 13th, 2021. See the published version at https://doi.org/10.1186/s12905-021-01294-5. 


\section{Abstract}

Background: Back pain (BP) is among the most common musculoskeletal problems globally and is a leading contributor to disability among adults. Millions of women especially those in low-income settings, engage in strenuous domestic activities that may increase their risk of BP.

The purpose of this meta-analysis was to estimate the association between physically demanding domestic work (PDDW) which is characterized as intensity, frequency, duration of work and biomechanical risk factors of work and BP among women.

Methods: Five databases were searched for records published from January 1991 to March 2020; and results from 11studies were included in the meta-analysis. A random effects model and the generic inverse-variance method was used to estimate the pooled odds ratio (OR), 95\% confidence interval $(\mathrm{Cl})$, and the degree of heterogeneity among studies $\left(\mathrm{I}^{2}\right)$. Stratified and sensitivity analyses were conducted to identify the influence of outliers and identify the sources of heterogeneity. Results: Exposure to high physically demanding domestic work was significantly associated with $\mathrm{BP}(\mathrm{OR}=1.63 ; 95 \% \mathrm{Cl} 1.30,2.04$; $\left.1^{2}=70 \%\right)$. The odds of back pain were highest among the following groups: women performing domestic work in non-neutral postures (OR=2.30;95\% $\mathrm{Cl}=1.75-3.04 ; \mathrm{I}^{2}=0 \% ; \mathrm{N}=4$ studies) and among women from low and middle income countries ( $\mathrm{OR}=1.98 ; 95 \% \mathrm{Cl}=1.58-2.49 ; \mathrm{I}^{2}=29 \% ; \mathrm{N}=5$ studies $)$. We found no evidence of publication bias (Egger's test $p$-value $=0.15$ ).

Discussion: PDDW may significantly increase a woman's risk of experiencing BP, but larger prospective studies are needed to further investigate the association. Presenting data on how domestic work affects the musculoskeletal health of women will be important in designing future interventions (behavioral, infrastructural and ergonomic) that can reduce domestic work burden

\section{Background}

Back pain (BP) includes acute (less than 6 weeks), chronic (pain lasting more than 12 weeks), or neuropathic pain in the upper or lower back. BP is a leading contributor to disability and activity limitation and has been estimated to account for $37 \%$ of the global burden of musculoskeletal disorders (MSDs) [1]. In addition, low back pain (LBP) remains the leading cause of years lived with disability (YLDs) among adults, accounting for 64.9 million YLDs [2]. Although BP can be a self-limiting condition, the reoccurrence rate is high (approximately 60\%) and individuals are likely to experience another episode within 3-6 months [2,3]. Limitation of activities because of LBP may result in loss of productive work time, increased medical expenditure, and further entrenchment of low-income individuals in poverty $[4,5]$.

The most common risk factors for BP include demographic characteristics, personal health habits, psychological factors, occupational exposures, and other chronic comorbidities [4, 6-11]. Prior reviews have established heavy manual work, non-neutral work postures (bending and twisting, repetitive motions, and long working hours) as risk factors for BP among occupational populations $[8,9,12,13]$. 
Biological sex and gender are also risk factors; females have a higher prevalence of LBP in the general population than men ([14-17]. A global burden of disease study found that the age-standardized prevalence of LBP is also higher among women than men [2].

The gendered difference in BP has been attributed to several occupational factors, such as differential exposures to work-related physical and physiological factors, male-oriented tool and workstation designs, and gendered variation in the perception of pain $[11,18-20]$. Generally, women tend to be clustered in specific occupations with different pattern of employment and exposures from those of men [21]. However, several occupational studies and reviews have shown that women-dominated jobs may be just as physically taxing as male-dominated jobs $[11,16,17,22-24]$. Thus, women's unique occupational exposures may place them at risk for MSDs, including BP [21].

Additionally, millions of women experience strenuous daily work conditions in low-waged or unpaid domestic labor, often in addition to a formal job. Women's domestic labor, which involves tasks such as cleaning, cooking, water fetching, manual washing of clothes, and family care duties, may be as physically, emotionally and time demanding as structured paid work [25-29]. In some LMICs, women spend an average of 10 hours per day engaged in strenuous domestic task in awkward postures [30]. Yet, few studies have examined the effects of the physical demands of domestic work (PDDW) on the musculoskeletal health of women. Social norms dictate domestic work as a woman's duty in many lowand middle-income countries (LMICs). This may discourage spousal and familial involvement in domestic roles even while women increasingly participate in the paid workforce. The double-burden of exposure from paid and unpaid work is particularly problematic among low-income populations where there are limited social services to relieve burdens $[28,31,32]$.

Few systematic reviews have assessed gender-specific relationships between PDDW and BP in the general population [33,34]. Previous meta-analyses of the relationship between non-occupational physical activities (such as sporting, commuting and domestic physical activities) and BP combined results from different types of non-occupational physical activities and did not present stratified results from domestic work demands $[33,35]$. Some of these reviews were also limited to studies published in English [33, 36].

Currently, no meta-analysis has assessed the association between PDDW and BP among women. This systematic review aims to fill this gap by examining the contribution of PDDW to the risk of BP among women. We included research studies that both defined domestic work exposures and presented femalespecific effect estimates. We also conducted subgroup analysis by country type (high income countries versus LMICs) and definitions of exposure to explore how these issues influence the relationship between PDDW and BP.

\section{Methods}

\subsection{Design and Search Strategy}


A systematic literature search was conducted to identify records published from January 1991 to March 2020 in PubMed, Embase, Web of Science, Scopus, and CINAHL, using search terms and keywords related to the population of interest, the exposure, and the outcome (" back pain" or "musculoskeletal symptoms"), without language restrictions. Google Scholar and the reference lists of relevant articles were searched for additional citations. This meta-analysis was performed and reported based on the Meta-analyses of Observational Studies in Epidemiology (MOOSE) criteria and in accordance with the Preferred Reporting Items for Systematic Reviews and Meta-Analyses (PRISMA) checklist [37, 38].

\subsection{Eligibility Criteria.}

Included studies were those that were published in peer-reviewed journals; assessed unpaid domestic work exposures; focused specifically on women, or women represented at least $50 \%$ of study sample and gender-stratified effects were presented; described at least one type of domestic task done by women; included women 18-59 years of age; and reported data needed to derive the measure of effect and the corresponding $95 \% \mathrm{Cl}$. Studies that were anecdotal, case series, editorials and reviews were excluded. Studies were also excluded if they focused only on occupational (paid) domestic work; included only elderly (over age 65 years) or pregnant women; included a predominantly male sample; did not present gender-specific effects; included acute musculoskeletal injuries (e.g., from slips/trips/falls or other traumatic events) or focused on MSDs in body areas other than the back (e.g., shoulder pain and carpal tunnel syndrome) as the outcome; included participants with BP secondary to a specific disease (e.g., osteoporosis and cancer); described exposure based solely on the woman's role (e.g., "housewives") but not on PDDW; focused on caregiving for disabled persons; or did not report effect estimates separately for unpaid domestic work exposures.

\subsection{Data Extraction.}

Two reviewers $(\mathrm{AO}$ and $\mathrm{CH})$ independently reviewed and abstracted information from potential studies after duplicate reports had been removed. Disagreements were resolved by consensus and discussion with a third reviewer (SI). The following information was abstracted: author, the year of publication, country of study, study design, proportion of the sample that included women, results stratified by gender (yes/no/not applicable), at least one type of domestic tasks is specified (yes/no), mean age of women participants, study sample size, numbers in exposed and unexposed groups, definition of BP, measures of domestic work exposures.

\subsection{Assessment of Study Quality.}

The Newcastle-Ottawa Scale for Observational Studies [39] was used to evaluate the risk of bias among the studies identified for inclusion. Some modifications were made to the scale based on the study design (Supplemental Table 1), For example, criteria for exposure definition were modified in the scale. The assessment was conducted by two reviewers $(\mathrm{AO}$ and $\mathrm{CH})$ independently. Disagreements were resolved by discussion or consultation with a third reviewer $(\mathrm{SI})$. The scale, totaling 10 points, evaluates the risk of bias from three domains: the selection of the study sample (representativeness of sample/cases, adequacy of sample size, response rates, definition and ascertainment of exposure and 
definition of cases and controls), comparability of study groups (potential confounding variables), and conceptualization of outcome (outcome definition and ascertainment, appropriateness of statistical measures). Quality scores were categorized as high ( $\geq 8$ points), moderate (6-7 points), or low ( $\leq 5$ points). For the risk of bias plots, the Robvis visualization tool was used to categorize and color-code each element in the three domains based on high risk, some concerns, and low risk of bias [40].

\subsection{Definition of Outcome and Exposure Variables.}

The outcome was defined as either self-reported pain/discomfort in the back area (upper, lower, or nonspecific) or care-seeking for BP. We included studies regardless of recall period used to ascertain selfreported back pain status. PDDW, which is the exposure variable, were expected to be assessed differently across studies because the dimension of work exposures is typically characterized in terms of frequency, intensity, and duration [41]. Therefore the exposure variable included those that categorized PDDW in terms of the magnitude of work (heavy or light PDDW), or assessed the duration of domestic work (time spent on domestic work per week/per day), or assessed the frequency/time spent working in awkward postures or history of forceful lifting.

\subsection{Data Synthesis and Statistical Analysis.}

The primary analytic objective was to estimate, using exposure and outcome data abstracted from each included study, a pooled estimate of association PDDW and BP. We also conducted subgroup analyses by country status (high versus low- and middle-income countries), by definitions of exposure (time, frequency/intensity of work, and biomechanical factors), and focus on gender (women only versus studies with both male and female included). If a study examined all the types of PDDW exposure, only the biomechanical exposure was analyzed. Stratified analyses were performed based on the study quality (i.e., high/moderate/low) and whether effect estimates were adjusted to control for confounding (yes/no).

Since most studies used a cross-sectional design, the OR was used as the measure of association. Measures of effect from included studies were pooled using the natural logarithm of the ORs (logOR), and the OR from each study was weighted by the inverse of its variance. Unadjusted ORs were used if adjusted ORs were not provided. When no effect estimate was given, the unadjusted OR was calculated directly from the abstracted information. A random-effects model was used to estimate the pooled OR and the $95 \% \mathrm{Cl}$ [42]. The data were pooled in Microsoft Excel, analyzed in the Review Manager (RevMan) version 5.3 program [43] and with the package 'meta' in $\mathrm{R}$ [44].

Heterogeneity among studies was examined by using the Cochran's $Q$ test and quantified using the Higgins $I^{2}$ statistic [45]. We set the criterion for a statistically significant Cochrane $Q$ test to $p<0.1$. The degree of heterogeneity was defined as low $\left(1^{2}<=25 \%\right)$, moderate $(26-50 \%)$, high $\left(1^{2}=51-75 \%\right)$, and very high $\left(I^{2}>75 \%\right)$. Publication bias was assessed using funnel plots and Egger's test $[46,47]$. The Leave-oneout method, and Baujat Plot, were used to investigate the effect of outliers and influencers on the degree 
of heterogeneity. We conducted sensitivity analyses to examine the influence of outliers and influencers, studies with low quality scores, or those that did not adjust for confounders on the Pooled OR.

\section{Results}

\subsection{Study Selection Process}

Figure 1 shows the detailed results of the identification and study selection process. We retrieved 1,358 non-duplicate records through search of databases and references from relevant articles. Following review of titles and abstracts 1,311 studies were excluded based on the following: not relevant to the outcome of interest (disabilities, domestic violence, infectious diseases, surveillance data, or acute musculoskeletal injuries), not relevant to the exposures or outcome of interest, not relevant to the population of interest, or were reports, reviews, case series or editorials. Forty-seven full text articles were subsequently assessed for eligibility and 36 were excluded as shown in Fig. 1. And Supplemental Table 4.

\subsection{Study Characteristics}

Supplemental Table 1 summarizes the characteristics of included studies. There were 101,394 total women included across the eleven studies, with sample sizes ranging from 73 to 64,348 women. Mean age of participants ranged from 29-49 years across studies. Six studies included samples from highincome countries [48-53] and five studies were included samples from LMICs (Ghana/South Africa, Bangladesh, Sri Lanka, Brazil, Lebanon) [25, 54-57].

Seven studies recruited only women $[25,48,50,52-54,57]$, three studies either had a sample that included at least $50 \%$ women or reported gender-stratified results $[49,51,55]$, and one large-scale study did not specify the number of women recruited but stratified results by gender [56]. All studies specified common domestic tasks done by women (e.g. cleaning, cooking, child caregiving). Four studies were on full-time housewives/homemakers $[25,50,54,57]$ while the remaining eight included women with paid employment.

Three studies categorized PDDW as number of hours per week performing domestic tasks [50-52] four studies categorized exposure as biomechanical (lifting, carrying, working in static and awkward postures) $[25,54,55,57]$ and the rest categorized PDDW based on intensity (heavy or light) and frequency of work $[48,49,53,56]$. In all included studies, exposure information was ascertained by self-report (i.e. questionnaire). Eight out of eleven studies included in this review were on low back pain while the remaining three were on chronic back pain, care-seeking for low back pain and upper back pain. The only case-control study defined outcome as care-seeking for low back pain [52] while the rest used selfreported (7 days, 1, 3, or 12 months) BP. All studies except one reported ORs adjusted for relevant confounders such as age, education, occupation, income and psychosocial factors of paid work.

\subsection{Quality Assessment.}


Using the Newcastle Ottawa Scale, six studies were categorized as high quality (8 points and above), four as moderate quality ( 6 and 7 points), and one as low-quality ( 5 points). The Robvis visualization plot in Fig. 2 shows that most studies have low risk of bias in most of the sub-domains except for assessment of non-respondents (a subdomain of selection of study participants). The quality assessment table and Robvis plot are depicted in Supplemental Table 2 and Fig. 2, respectively.

\subsection{Overall association between domestic work demands and BP.}

The pooled odds ratio from eleven studies showed that high PDDW, characterized as long duration, high frequency and intensity, or high biomechanical demand (awkward posture and lifting heavy objects), was significantly associated with $\mathrm{BP}$ among women $(\mathrm{OR}=1.63 ; 95 \% \mathrm{Cl}=1.30-2.04 ; \mathrm{Fig} .3)$. However, there was substantial heterogeneity among the included studies (Cochrane Q-test $p$-value $<0.01 ; I^{2}=70 \%$; Fig. 3).

\subsection{Identifying and Quantifying Heterogeneity. 3.5.1 Outlier and Influential Analysis.}

The Baujat diagnostic plot (Supplemental Fig. 1) showed that Alzaharani et al. [49] contributed to the overall heterogeneity to the greatest extent and had the most influence on the overall pooled OR, likely due to the large sample size compared to the other studies. Influential analysis, using the leave-one out method (Supplemental Fig. 2), also revealed that Alzaharani et al. [48] was the predominant source of heterogeneity. The lowest $\mathrm{I}^{2}$ value (16\%) was observed when the Alzaharani et al. [49] was removed from the analysis. Omitting Habib and Rahman[53]the study with the greatest effect size $(\mathrm{OR}=6.00 ; 95 \% \mathrm{Cl}=$ 1.57-22.88), did not meaningfully influence the pooled effect size $(\mathrm{OR}=1.57 ; 95 \% \mathrm{Cl}=1.26-1.95$; Supplemental Fig. 2) or the degree of heterogeneity $\left(l^{2}=69 \%\right)$.

\subsubsection{Subgroup analysis.}

Subgrouping studies based on definitions of exposure (hours/week of domestic work, frequency or intensity of domestic task per week, and presence of biomechanical factors such as lifting, carrying and awkward postures), resulted in variation of the pooled odds ratio across groups (1.29-2.30) (Fig. 4). The test for between-group heterogeneity was statistically significant $(Q=7.48, p$-value $=0.02$ (Supplemental Table 3). Within-group heterogeneity was reduced for studies that defined exposure as a function of time $\left(\mathrm{OR}=1.59 ; 95 \% \mathrm{Cl} 1.16-2.18 ; \mathrm{I}^{2}=0 \% ; \mathrm{N}=3\right.$ studies $)$ or by biomechanical exposure $(\mathrm{OR}=2.30 ; 95 \% \mathrm{Cl}$ $1.75-3.04 ; I^{2}=0 \% ; N=4$ studies) (Fig. 4), compared to studies that defined exposure based on work intensity or frequency $\left(\mathrm{OR}=1.29 ; 95 \% \mathrm{Cl} 0.94-1.79 ; \mathrm{I}^{2}=82 \% ; \mathrm{N}=4\right.$ studies $)$, due to the influential effect of Alzaharani et al. [48].

Subgrouping studies based on country status (Fig. 5) showed that there was significant between-group heterogeneity $(Q=11.22 ; P=0.0008$; Supplemental Table 3$)$. Within-group heterogeneity was reduced among high-income $\left(\mathrm{OR}=1.21 ; 95 \% \mathrm{Cl} 1.02-1.45 ; \mathrm{I}^{2}=15 \% ; \mathrm{N}=6\right.$ studies $)$ and LMICs subgroup (OR = 
$1.98 ; 95 \% \mathrm{Cl} 1.58-2.49 ; \mathrm{I}^{2}=29 \% ; \mathrm{N}=5$ studies$)$ when compared to the heterogeneity $\left(\mathrm{I}^{2}=70 \%\right)$ within all included studies as shown in Fig. 5. Studies from LMICs had a stronger association between physically demanding domestic work and back pain than studies from high-income countries. When studies were sub-grouped by gender specificity (Fig. 6), studies with samples of only women had a stronger association between physically demanding domestic work and back pain (OR $=1.72 ; 95 \% \mathrm{Cl} 1.41-2.11$; $\mathrm{I}^{2}=30 \% ; \mathrm{N}=8$ studies $)$ than studies with samples of both men and women $(\mathrm{OR}=1.44 ; 95 \% \mathrm{Cl} 0.922 .23$; $1^{2}=72 \% ; N=3$ studies).

\subsubsection{Stratified analysis.}

Compared to the overall pooled OR of 1.63 , slightly lower effect sizes were observed when considering only studies categorized as high quality (OR $=1.5495 \% \mathrm{Cl} 1.18-2.02 ; \mathrm{I}^{2}=80 \% ; \mathrm{N}=6$ studies, Supplemental Fig. 3) and when omitting the one study[53] (Habib MM and Rahman 2015) that did not provide an adjusted $\mathrm{OR}(\mathrm{OR}=1.57 ; 95 \% \mathrm{Cl}=1.26-1.95 ; \mathrm{I} 2=69 \% ; \mathrm{N}=10$ studies; omitting Habib $\mathrm{MM}$ and Rahman (2015), in Supplemental Fig. 2). Heterogeneity increased from $70 \%\left(\mathrm{I}^{2}\right.$ from pooled effect estimate) to $80 \%$ when the pooled analysis included only high-quality studies (Supplemental Fig. 3). When stratifying by type of study design, excluding the only case-control study Josephson et al. (2003) did not meaningfully influence pooled effect estimate nor the degree of heterogeneity $(O R=1.66 ; 95 \% \mathrm{Cl}$ $=1.31-2.11 ; \mathrm{N}=10$ studies; Supplemental Fig. 2)

\subsubsection{Publication Bias.}

The funnel plot, a plot of the odds ratios against the standard errors from each included study appears symmetrical, suggesting limited evidence of publication bias (Supplemental Fig. 4). This conclusion is also supported by the result of the Egger's test $(p=0.15)$.

\section{Discussion}

\subsection{General Discussion}

To the best of our knowledge, this is the only synthesis of observational studies that assessed the association between PDDW and BP while comparing estimates based on country status and standardized dimensions of physical work exposures (frequency, duration and magnitude). Our results demonstrated that women who perform high PDDW, characterized as long time spent on work, frequency and magnitude (heavy workload) and the presence of biomechanical risk factors (activity conducted in non-neutral posture) have a higher odds of BP compared to women who perform low PDDW. The magnitude and direction of the pooled estimates from the overall and subgroup analyses did not change meaningfully when the major source of heterogeneity was omitted and when analyses were restricted to high quality studies.

Standard operationalization of biomechanical exposure comprises three main dimensions; level or magnitude, repetitiveness or frequency, and duration of work. Exposures in the included studies were 
described in self-reported magnitudes, frequency and duration of domestic tasks such as carrying, lifting, pushing as well as self-reported frequency or duration of working in awkward postures and lifting. Biomechanical loading from manual material handling activities and working in awkward postures are established risk factors for both recurrent and chronic back pain [34]. This agrees with our results, specifically that the pooled OR from studies in which exposures were defined based on biomechanical characteristics of domestic work was greater than the pooled ORs from studies in which exposures were defined in more generic terms (e.g., time spent performing domestic work).

We did not identify any prospective studies to include in the analyses, and a previous review of both occupational and non-occupational risk factors for LBP did not include domestic work exposures [34]. We are unaware of other studies assessing the association between PDDW among women specifically, although one review of prospective studies found that women in the general population had a higher prevalence of low back pain compared to men [11]. The gender differences in prevalence of BP could be due in part to women in many regions of the world being disproportionately exposed to physically demanding domestic work. The results of this study suggests that the physical demands of unpaid domestic work and its musculoskeletal health risks should be more recognized and examined in occupational research, especially in LMICs where millions of low-income women are exposed to strenous daily work conditions that are comparable to work in occupational environments.

A prior systematic review of 35 studies assessed the association between occupational lifting and low back pain and concluded that it is unlikely that occupational lifting is independently associated with LBP [13]. Another systematic review found no significant relationship between free-living physical activity (classified as leisure-time physical activity) and non-specific LBP [58]. The result of the former review may be different from ours because we included studies that examined non-neutral postures as biomechanical risk factors rather than just the activity of lifting. Also, our study assessed domestic physical activity among women in the household, not workplace physical activity. For the latter prior review, domestic physical activity was classified as a component of leisure time physical activity, which could have influenced the exposure-outcome relationship.

Our results revealed a higher prevalence of BP in LMICs when compared to higher income countries. This agrees with other reviews studies where the prevalence of LBP among studies from LMICs was higher than those from high income countries although the studies did not consider gender-specific effects [59, 60]. The higher odds of BP from pooled effect estimates from LMICs indicate that the impact of domestic work on women's health may be more severe in LMICs. The biomechanical demands of domestic work on women may be elevated where water infrastructure is lacking, or unreliable and water carrying/porterage is common [61]. Water carriage has long- and short-term impacts on musculoskeletal health of women [29].

In addition to water insecurity and carriage, daily domestic tasks such as caregiving activities and manual food processing could increase the risk of BP [27]. Women from developed economies may have less strenuous domestic work demands than low-income women in LMICs as a result of differences in 
social/cultural expectations, better bargaining power due to higher paid income, increased use of mechanized household devices (e.g. dishwashers, laundry machines), and more social support/spousal involvement in performing domestic tasks. Similarly, middle-to-high income women in LMICs who have access to similar social and environmental resources might also face lower domestic work health risks. These differences in domestic work demands partially explain why domestic work has traditionally been regarded as a 'non-occupational or leisure-time' physical activity with protective effects in published studies and reviews from developed countries [33-35].

\subsection{Methodological considerations: Study Inclusion and Classification}

The current study used well-defined inclusion and exclusion criteria to ensure that studies containing the intended target population (women) were selected. We excluded studies focused on women taking care of persons with disabilities and elderly women out of concern their level of exposure would not be generalizable to the overall population and because there is causal association between advanced age and low back pain [11]. We also excluded studies that did not fully provide exposure and outcome information to reduce the threat of differential misclassification of exposure or outcomes. We included studies examining acute and chronic back pain. We believe our inclusion/exclusion criteria were appropriate given that prior meta-analyses of non-occupational exposures and back pain have not assessed the impact of the domestic work or focused on gendered effects.

\subsection{Strengths and Limitations}

The strengths of this review include: (1) extensive literature searches and inclusion of a study not published in English; (2) included studies were mostly of moderate to high quality and adjusted for relevant confounders; (3) identification of major sources of heterogeneity; (4) absence of publication bias; (5) Estimation of gender-specific association of domestic work with back pain. Almost all (six out eight) studies that sampled women engaged in paid work adjusted for physical demands of paid work and other relevant demographic factors during data analysis.

Several limitations should be considered when interpreting the findings from this study. Since the exposure and outcome information in most of the included studies were obtained using self-report methods, the results could be subject to reporting bias. Further, the temporal relationship between exposure to PDDW and BP cannot be established because most studies were cross-sectional, and we did not find any prospective cohort study to include in this meta-analysis [34]. Other potential sources of bias were those relating to study selection such as adequacy of sample size, response rate reporting, and comparability between respondents and non-respondents.

Furthermore, few of the included studies reported information regarding the validity of the instrument used ascertain domestic work exposures. In addition, there were considerable methodological differences across the included studies in the measurement of domestic work exposures, which may have led to misclassification of domestic work demand in our analyses [62]. Likewise, the definition, presenting 
symptoms, severity and period prevalence (ranges from one week to a year) of back pain differed across studies. These variations in exposure and outcome measurements across studies may have impacted both the magnitude and precision of our pooled OR estimates. Finally, since most studies ascertained both exposure and outcome by self-report, common method bias may have created the appearance of an association[63].

\subsection{Implications and recommendations for research}

Results of the current study suggest an association between the phyiscal demands of unpaid domestic work and BP, particularly among women in LMICs. Back pain is not typically a priority for mitigation because it is neither life-threatening nor as dangerous as other diseases prevalent in LMIC, yet it can cause long-lasting disability and declines in wellbeing and economic opportunity [59,60]. Presently, gender-specific research investigating domestic exposures and musculoskeletal pain among women are limited $[16,22]$. Presenting data on how domestic work affects the musculoskeletal health of women will be important in designing future interventions (behavioral, infrastructural and ergonomic) that can reduce domestic work burden.

Most published large-scale studies that have assessed domestic work impact on musculoskeletal disorders mostly ascertain exposures using a woman's work role (housewives) and self-report of exposure $[33,64,65]$. Relying solely on self-report information of exposures collected at one point in time from participants may be imprecise or lead to misclassification of exposure especially in routine daily activities such as domestic work [66]. Likewise, more information should be collected on pain experiences beside 'absence or presence of pain' to correctly ascertain the presence and severity pain in future studies $[67,68]$. Future research should use objective measures of exposure, such as observation or instrumentbased tools, to quantify the physical demand of domestic work so that exposure information is rigorous and can be standardized across studies [69]. Using a pain ratings scale, visual diagrams, specific recall period and probes to evaluate type of pain symptoms or level of impairment will be invaluable in reducing heterogeneity across studies, improving stability of estimates and generalization of findings. More longitudinal studies are needed to estimate the day-to-day variances in domestic work, and to quantify the physical demands on women's bodies from domestic work, before we can fully understand its causal relationship with BP.

Policymakers and labor organizations should put more concerted efforts in recognizing unpaid domestic work as an occupation with health risks like those experienced in paid domestic occupations, which will aid in meeting global sustainable development goals for gender equity and women's health.

\subsection{Conclusion}

Results of the current study suggests that PDDW is associated with BP, especially among women from LMICs. Large prospective studies in LMICs are needed to critically examine or establish the relationship between domestic physical activity and BP.

\section{Abbreviations}


PDDW

Physically demanding domestic work

BP

Back Pain

LBP

low Back Pain

OR

Odds Ratio

$\mathrm{Cl}$

Confidence Interval

LMICs

Low- and Middle-Income Countries

MSDs

Musculoskeletal Disorders

\section{Declarations}

\section{Ethics and consent to participate}

Not applicable

\section{Consent for Publication}

Not applicable

\section{Availability of data and Materials}

The data analysed were abstracted from published articles, other data generated are available in the supplemental file.

\section{Competing Interests}

The authors declare that they have no competing interests.

\section{Funding}

None declared

\section{Author's Contribution}

A.O: Conceptualization, Methodology, Literature Search, Formal analysis, Writing-Original Draft, Visualization.

C.H: Data Screening and Validation, Writing-Review, Editing. 
S.I: Validation, Writing-Review and Editing.

M.S: Methodology, Formal Analysis, Writing - Review \& Editing.

N.F: Methodology Writing-Review \& Editing, Visualization.

KKB: Writing - Review \& Editing and Supervision

All Authors: Read and approved final manuscript.

Acknowledgements

Not applicable

\section{References}

1. Palazzo C, Ravaud JF, Papelard A, Ravaud P, Poiraudeau S: The burden of musculoskeletal conditions. PloS one 2014, 9(3):e90633.

2. Wu A, March L, Zheng X, Huang J, Wang X, Zhao J, Blyth FM, Smith E, Buchbinder R, Hoy D: Global low back pain prevalence and years lived with disability from 1990 to 2017: estimates from the Global Burden of Disease Study 2017. Ann Trans/ Med 2020, 8(6):299-299.

3. Buruck G, Tomaschek A, Wendsche J, Ochsmann E, Dorfel D: Psychosocial areas of worklife and chronic low back pain: a systematic review and meta-analysis. BMC Musculoskelet Disord 2019, 20(1):480.

4. Froud R, Patterson S, Eldridge S, Seale C, Pincus T, Rajendran D, Fossum C, Underwood M: A systematic review and meta-synthesis of the impact of low back pain on people's lives. $B M C$ Musculoskeletal Disorders 2014, 15(1):50.

5. Hoy D, March L, Brooks P, Blyth F, Woolf A, Bain C, Williams G, Smith E, Vos T, Barendregt J et al: The global burden of low back pain: estimates from the Global Burden of Disease 2010 study. Annals of the rheumatic diseases 2014, 73(6):968-974.

6. Kopec JA, Sayre EC, Esdaile JM: Predictors of Back Pain in a General Population Cohort. Spine 2004, 29(1):70-77.

7. Leboeuf-Yde C: Smoking and low back pain. A systematic literature review of $\mathbf{4 1}$ journal articles reporting 47 epidemiologic studies. Spine 1999, 24(14):1463-1470.

8. Kwon BK, Roffey DM, Bishop PB, Dagenais S, Wai EK: Systematic review: occupational physical activity and low back pain. Occupational medicine (Oxford, England) 2011, 61(8):541-548.

9. Wai EK, Roffey DM, Bishop P, Kwon BK, Dagenais S: Causal assessment of occupational carrying and low back pain: results of a systematic review. Spine $J$ 2010, 10(7):628-638.

10. Ibrahimi-Kaçuri D, Murtezani A, Rrecaj S, Martinaj M, Haxhiu B: Low back pain and obesity. Med Arch 2015, 69(2):114-116. 
11. Wang YX, Wang JQ, Kaplar Z: Increased low back pain prevalence in females than in males after menopause age: evidences based on synthetic literature review. Quant Imaging Med Surg 2016, 6(2):199-206.

12. Coenen P, Gouttebarge V, van der Burght AS, van Dieen JH, Frings-Dresen MH, van der Beek AJ, Burdorf $A$ : The effect of lifting during work on low back pain: a health impact assessment based on a meta-analysis. Occupational and environmental medicine 2014, 71(12):871-877.

13. Wai EK, Roffey DM, Bishop P, Kwon BK, Dagenais S: Causal assessment of occupational lifting and low back pain: results of a systematic review. Spine J 2010, 10(6):554-566.

14. Bener A, Dafeeah EE, Alnaqbi K, Falah O, Aljuhaisi T, Sadeeq A, Khan S, Schlogl J: An epidemiologic analysis of low back pain in primary care: a hot humid country and global comparison. $J$ Prim Care Community Health 2013, 4(3):220-227.

15. Hoy D, Bain C, Williams G, March L, Brooks P, Blyth F, Woolf A, Vos T, Buchbinder R: A systematic review of the global prevalence of low back pain. Arthritis and rheumatism 2012, 64:2028-2037.

16. Strazdins L, Bammer G: Women, work and musculoskeletal health. Social Science \& Medicine 2004, 58(6):997-1005.

17. Wijnhoven HA, de Vet HC, Picavet HS: Prevalence of musculoskeletal disorders is systematically higher in women than in men. Clin J Pain 2006, 22(8):717-724.

18. Fatoye F, Gebrye T, Odeyemi I: Real-world incidence and prevalence of low back pain using routinely collected data. Rheumatol Int 2019, 39(4):619-626.

19. Landry LG: Preventing occupational injuries: women's perception of risk from musculoskeletal exposures. AAOHN journal : official journal of the American Association of Occupational Health Nurses 2006, 54(2):75-83.

20. World Health Organization (WHO): Gender, Work and Health. In. Department of Gender, Women and Health, WHO, Geneva, Switzerland: Interdisciplinary Centre for the study of Biology, Health, Society and the Environment (CINBIOSE), World Health Organization; 2011. https://www.who.int/occupational_health/publications/gender_work_health/en/

21. Landry LG: Characterization of Women's Occupational Musculoskeletal Exposures. AAOHN Journal 2007, 55(9):351-359.

22. Habib RR, Messing K: Gender, women's work and ergonomics. Ergonomics 2012, 55(2):129-132.

23. Messing K, Stock SR, Tissot F: Should studies of risk factors for musculoskeletal disorders be stratified by gender? Lessons from the 1998 Québec Health and Social Survey. Scandinavian Journal of Work, Environment \& Health 2009(2):96-112.

24. Messing K: Physical Exposures in Work Commonly Done by Women. Canadian journal of applied physiology = Revue canadienne de physiologie appliquée 2004, 29:639-656.

25. Habib RR, El Zein K, Hojeij S: Hard work at home: musculoskeletal pain among female homemakers. Ergonomics 2012, 55(2):201-211. 
26. Habib RR, Fathallah FA, Messing K: Full-time homemakers: workers who cannot "go home and relax". Int J Occup Saf Ergon 2010, 16(1):113-128.

27. Ojukwu CP, Anyanwu GE, Anekwu EM, Chukwu SC, Fab-Agbo C: Infant carrying methods: Correlates and associated musculoskeletal disorders among nursing mothers in Nigeria. J Obstet Gynaecol 2017, 37(7):855-860.

28. Sayer LC: Gender, Time and Inequality: Trends in Women's and Men's Paid Work, Unpaid Work and Free Time. Social Forces 2005, 84(1):285-303.

29. Geere JL, Cortobius M, Geere JH, Hammer CC, Hunter PR: Is water carriage associated with the water carrier's health? A systematic review of quantitative and qualitative evidence. BMJ Glob Health 2018, 3(3):e000764.

30. Blackden M, Wodon Q: Gender, Time Use, and Poverty: Introduction. In.: University Library of Munich, Germany; 2006.

31. Bethge $M$, Borngraber $Y$ : Work-family conflicts and self-reported work ability: cross-sectional findings in women with chronic musculoskeletal disorders. BMC Musculoskelet Disord 2015, 16:58.

32. Moreno N, Moncada S, Llorens C, Carrasquer P: Double presence, paid work, and domestic-family work. New Solut 2010, 20(4):511-526.

33. Alzahrani H, Mackey M, Stamatakis E, Zadro JR, Shirley D: The association between physical activity and low back pain: a systematic review and meta-analysis of observational studies. Sci Rep 2019, 9(1):8244.

34. Heneweer H, Staes F, Aufdemkampe G, van Rijn M, Vanhees L: Physical activity and low back pain: a systematic review of recent literature. Eur Spine J 2011, 20(6):826-845.

35. Shiri R, Falah-Hassani K: Does leisure time physical activity protect against low back pain? Systematic review and meta-analysis of 36 prospective cohort studies. British Journal of Sports Medicine 2017, 51(19):1410.

36. Elser H, Falconi A, Bass M, Cullen M: Blue-collar work and women's health: A systematic review of the evidence from 1990-2015. SSM - Population Health 2018, 6.

37. Stroup DF, Berlin JA, Morton SC, Olkin I, Williamson GD, Rennie D, Moher D, Becker BJ, Sipe TA, Thacker SB: Meta-analysis of observational studies in epidemiology: a proposal for reporting. Metaanalysis Of Observational Studies in Epidemiology (MOOSE) group. Jama 2000, 283(15):2008-2012.

38. Moher D, Liberati A, Tetzlaff J, Altman DG, The PG: Preferred Reporting Items for Systematic Reviews and Meta-Analyses: The PRISMA Statement. PLOS Medicine 2009, 6(7):e1000097.

39. Stang A: Critical evaluation of the Newcastle-Ottawa scale for the assessment of the quality of nonrandomized studies in meta-analyses. European journal of epidemiology 2010, 25(9):603-605.

40. McGuinness LA, Higgins JPT: Risk-of-bias VISualization (robvis): An R package and Shiny web app for visualizing risk-of-bias assessments. Research Synthesis Methods 2020.

41. Burdorf A, van der Beek A: Exposure assessment strategies for work-related risk factors for musculoskeletal disorders. Scandinavian Journal of Work, Environment \& Health 1999, 25:25-30. 
42. DerSimonian R, Laird N: Meta-analysis in clinical trials. Controlled clinical trials 1986, 7(3):177-188.

43. Web R: Review Mangaer Web (RevMan Web). In.: The Cochrane Collaboration; 2019.

44. Balduzzi S, Rücker G, Schwarzer G: How to Perform a Meta-analysis with R: a practical tutorial. Evidence-Based Mental Health 2019.

45. Woolf B: On estimating the relation between blood group and disease. Annals of human genetics 1955, 19(4):251-253.

46. Baujat B, Mahé C, Pignon J-P, Hill C: A graphical method for exploring heterogeneity in metaanalyses: Application to a meta-analysis of 65 trials. Statistics in medicine 2002, 21:2641-2652.

47. Egger M, Davey Smith G, Schneider M, Minder C: Bias in meta-analysis detected by a simple, graphical test. Bmj 1997, 315(7109):629-634.

48. Ahlgren C, Malmgren Olsson EB, Brulin C: Gender analysis of musculoskeletal disorders and emotional exhaustion: interactive effects from physical and psychosocial work exposures and engagement in domestic work. Ergonomics 2012, 55(2):212-228.

49. Alzahrani H, Shirley D, Cheng SWM, Mackey M, Stamatakis E: Physical activity and chronic back conditions: A population-based pooled study of 60,134 adults. Journal of Sport and Health Science 2019.

50. Fong KN, Law CY: Self-perceived musculoskeletal complaints: relationship to time use in women homemakers in Hong Kong. Journal of occupational rehabilitation 2008, 18(3):273-281.

51. Hubscher M, Ferreira ML, Junqueira DR, Refshauge KM, Maher CG, Hopper JL, Ferreira PH: Heavy domestic, but not recreational, physical activity is associated with low back pain: Australian Twin low BACK pain (AUTBACK) study. Eur Spine J 2014, 23(10):2083-2089.

52. Josephson M, Ahlberg G, Harenstam A, Svensson H, Theorell T, Wiktorin C, Vingard E: Paid and unpaid work, and its relation to low back and neck/shoulder disorders among women. Women \& health 2003, 37(2):17-30.

53. Rosano A, Moccaldi R, Cioppa M, Lanzieri G, Persechino B, Spagnolo A: [Musculoskeletal disorders and housework in Italy]. Annali di igiene : medicina preventiva e di comunita 2004, 16(3):497-507.

54. Habib MM, Rahman SU: Musculoskeletal symptoms (MSS) and their associations with ergonomic physical risk factors of the women engaging in regular rural household activities: A picture from a rural village in Bangladesh. Work (Reading, Mass) 2015, 50(3):347-356.

55. Geere JA, Bartram J, Bates L, Danquah L, Evans B, Fisher MB, Groce N, Majuru B, Mokoena MM, Mukhola MS et al: Carrying water may be a major contributor to disability from musculoskeletal disorders in low income countries: a cross-sectional survey in South Africa, Ghana and Vietnam. Journal of global health 2018, 8(1):010406.

56. Malta DC, Oliveira MM, Andrade S, Caiaffa WT, Souza MFM, Bernal RTI: Factors associated with chronic back pain in adults in Brazil. Rev Saude Publica 2017, 51(suppl 1):9s.

57. Ranasinghe PD, Atukorala I, Samaranayake A, Gunawardana NS: SAT0504 Prevalence and Correlates of Household Work Related Musculoskeletal Disorders in Low Back Region among Sri 
Lankan Housewives. Annals of the Rheumatic Diseases 2016, 75(Suppl 2):852-852.

58. Hendrick P, Milosavljevic S, Hale L, Hurley DA, McDonough S, Ryan B, Baxter GD: The relationship between physical activity and low back pain outcomes: a systematic review of observational studies. Eur Spine J 2011, 20(3):464-474.

59. Louw QA, Morris LD, Grimmer-Somers K: The prevalence of low back pain in Africa: a systematic review. BMC musculoskeletal disorders 2007, 8:105-105.

60. Morris LD, Daniels KJ, Ganguli B, Louw QA: An update on the prevalence of low back pain in Africa: a systematic review and meta-analyses. BMC Musculoskeletal Disorders 2018, 19(1):196.

61. Graham JP, Hirai M, Kim SS: An Analysis of Water Collection Labor among Women and Children in 24 Sub-Saharan African Countries. PLoS One 2016, 11(6):e0155981.

62. Pearce $\mathrm{N}$, Checkoway H, Kriebel D: Bias in occupational epidemiology studies. Occup Environ Med 2007, 64(8):562-568.

63. Wingate S, Sng E, Loprinzi PD: The influence of common method bias on the relationship of the socio-ecological model in predicting physical activity behavior. Health Promot Perspect 2018, 8(1):41-45.

64. Mattioli S, Baldasseroni A, Bovenzi M, Curti S, Cooke RM, Campo G, Barbieri PG, Ghersi R, Broccoli M, Cancellieri MP et al: Risk factors for operated carpal tunnel syndrome: a multicenter populationbased case-control study. BMC Public Health 2009, 9:343.

65. Mattioli S, Baldasseroni A, Curti S, Cooke RM, Mandes A, Zanardi F, Farioli A, Buiatti E, Campo G, Violante FS: Incidence rates of surgically treated idiopathic carpal tunnel syndrome in blue- and white-collar workers and housewives in Tuscany, Italy. Occupational and environmental medicine 2009, 66(5):299-304.

66. Spielholz P, Silverstein B, Morgan M, Checkoway H, Kaufman J: Comparison of self-report, video observation and direct measurement methods for upper extremity musculoskeletal disorder physical risk factors. Ergonomics 2001, 44(6):588-613.

67. Lenderink AF, Zoer I, van der Molen HF, Spreeuwers D, Frings-Dresen MHW, van Dijk FJH: Review on the validity of self-report to assess work-related diseases. International archives of occupational and environmental health 2012, 85(3):229-251.

68. Schierhout $\mathrm{GH}$, Myers JE: Is self-reported pain an appropriate outcome measure in ergonomicepidemiologic studies of work-related musculoskeletal disorders? Am J Ind Med 1996, 30(1):93-98.

69. Hansson G-Å, Balogh I, Byström J, Ohlsson K, Nordander C, Asterland P, Sjölander S, Rylander L, Winkel J, Skerfving S: Questionnaire versus direct technical measurements in assessing postures and movements of the head, upper back, arms and hands. Scandinavian journal of work, environment \& health 2001, 27:30-40.

\section{Additional Files}

Additional File, Table 1. Characteristics of Included Studies 
Additional File, Table 2. Risk of Bias and Overall Quality Rating using the New Castle Ottawa Scale

Additional File, Figure 1. Baujat Plot showing significant contribution to heterogeneity by Alzaharani 2019

Additional File, Figure 2. Forest Plot with each study's contribution to heterogeneity, omitted one at a time.

Additional File, Figure 3. Forest plot showing sensitivity analysis of high-quality studies, investigating the association between physically demanding domestic work and back pain in women

Additional File, Figure 4. Funnel plot to show presence or absence of publication bias

Additional File, Appendix showing search terms from PubMed and Embase

Figures 


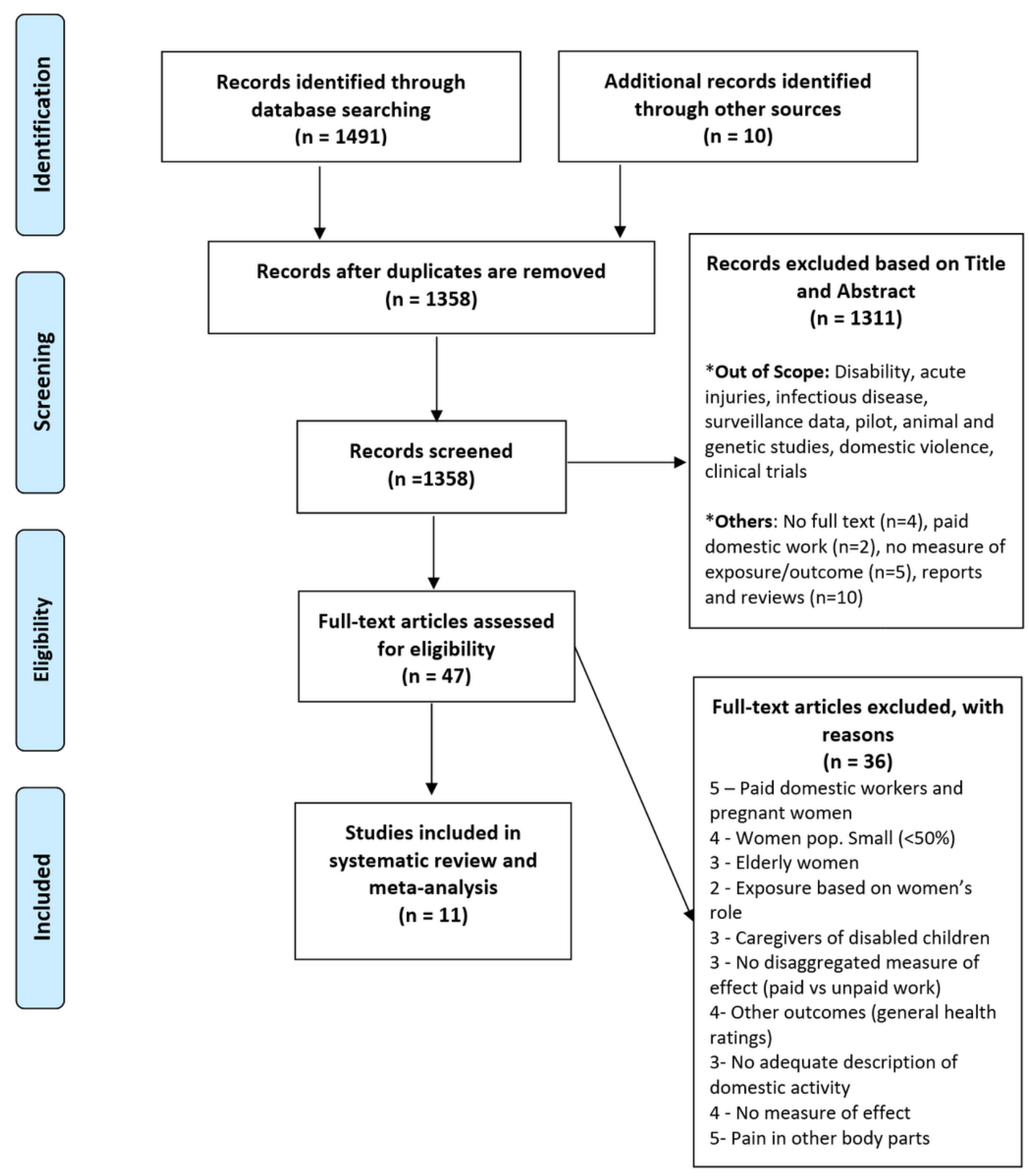

Figure 1

Flow of Studies through the Review 
Representativeness of Sample or cases and Control

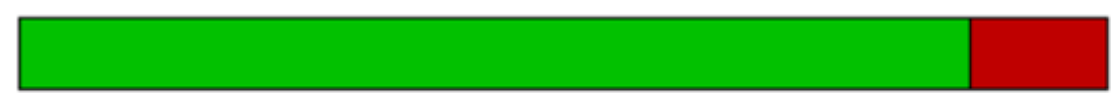

Sample Size

Non respondents

Asertainment of Exposure

Confounders Adjusted

Assessment of Outcome
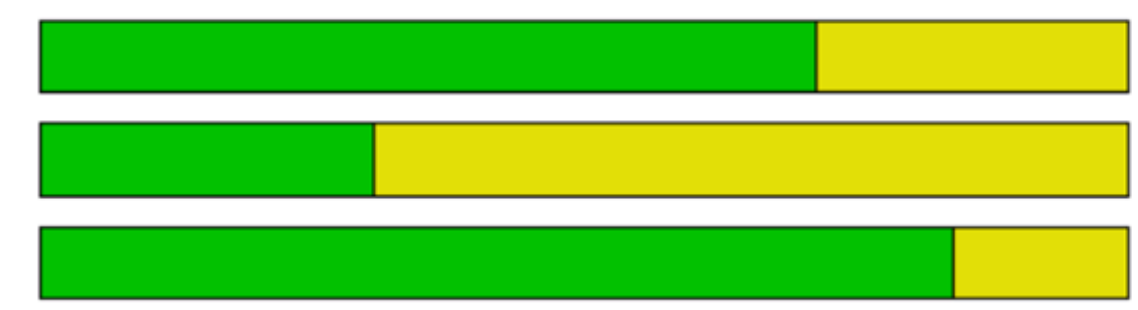

d
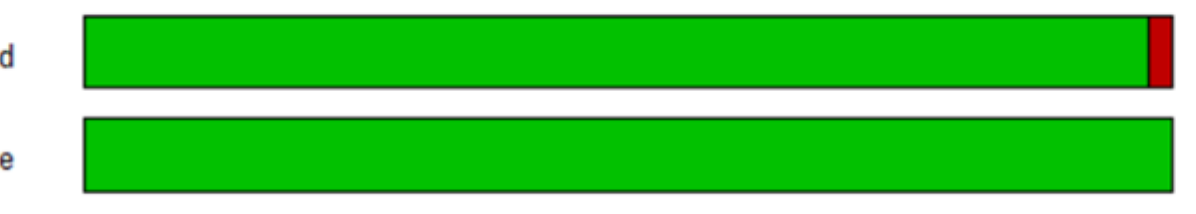

Appropriate Statistical test

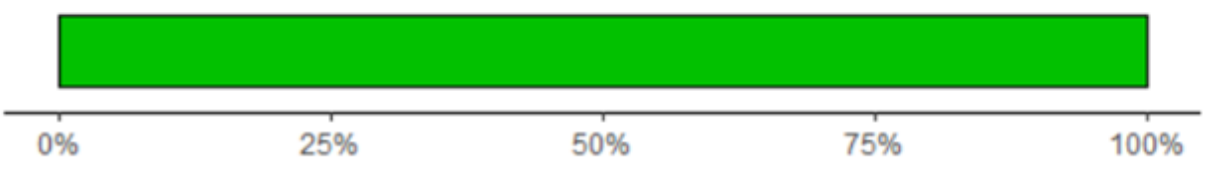

Low risk of bias

Some concerns

High risk of bias

\section{Figure 2}

RobVis (Risk of Bis Visualization) Plot

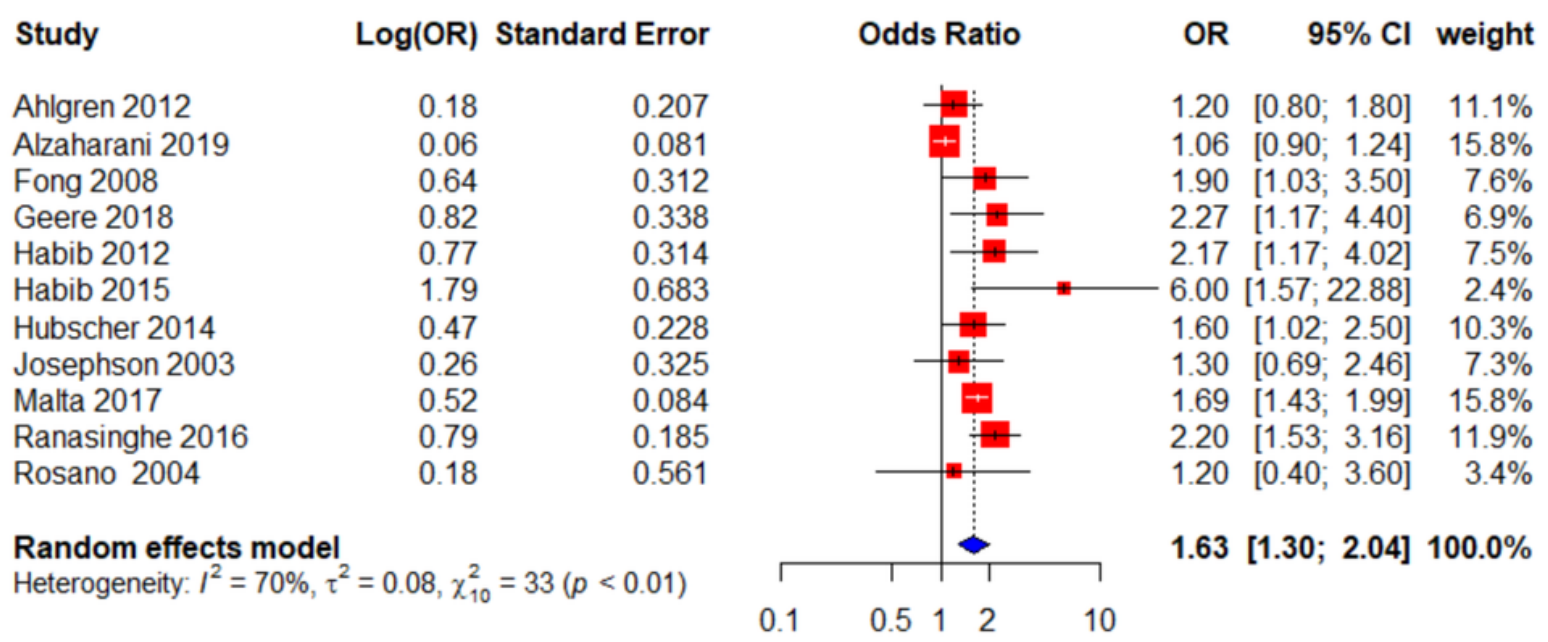

\section{Figure 3}

Forest plot of all studies investigating the association between physically demanding domestic work and back pain in women. Odds ratio (OR); Confidence Interval $(\mathrm{Cl})$. 


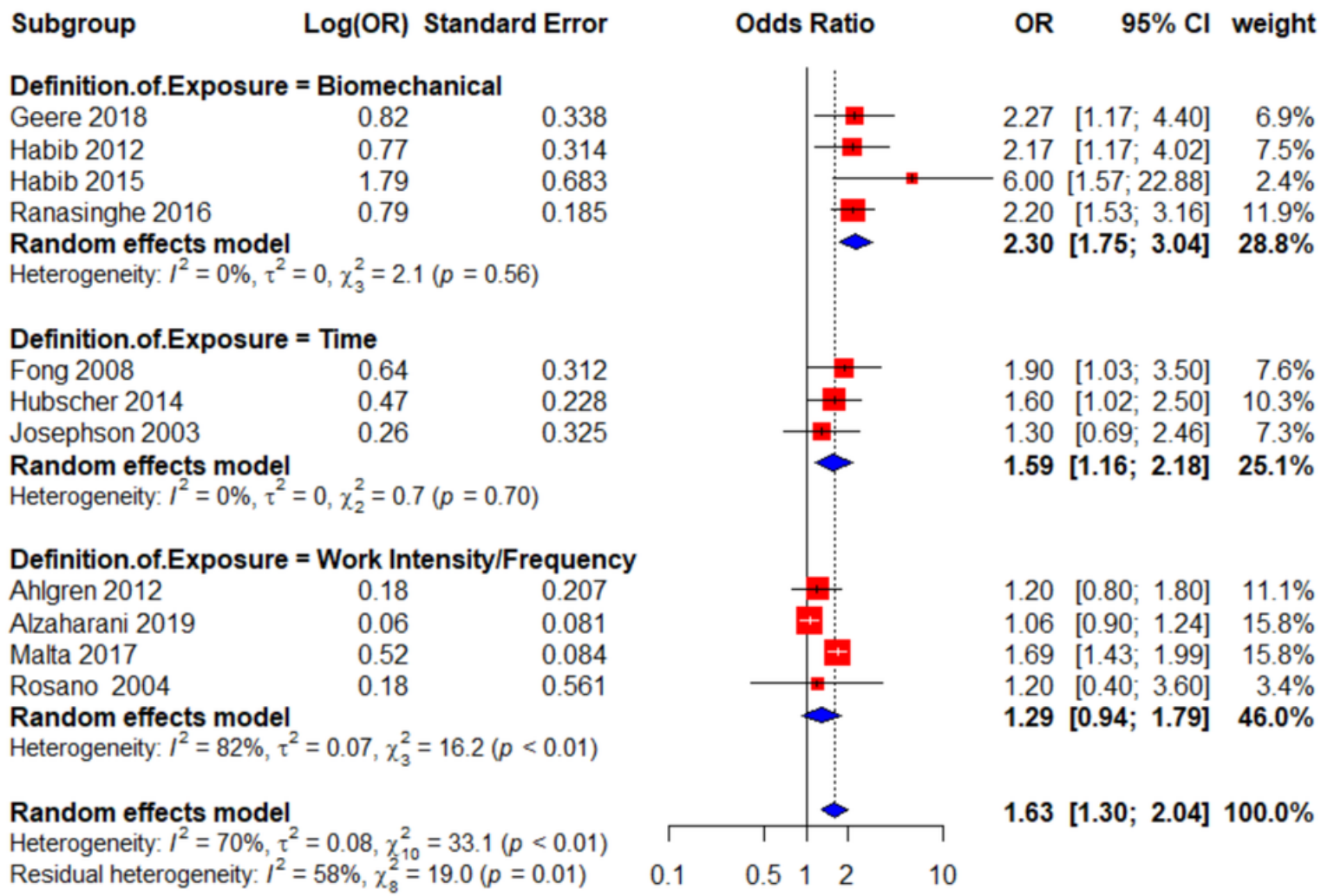

\section{Figure 4}

Forest plot of subgroup analysis based on exposure definition, investigating the association between physically demanding domestic work and back pain in women. Odds ratio (OR); Confidence Interval (Cl). 


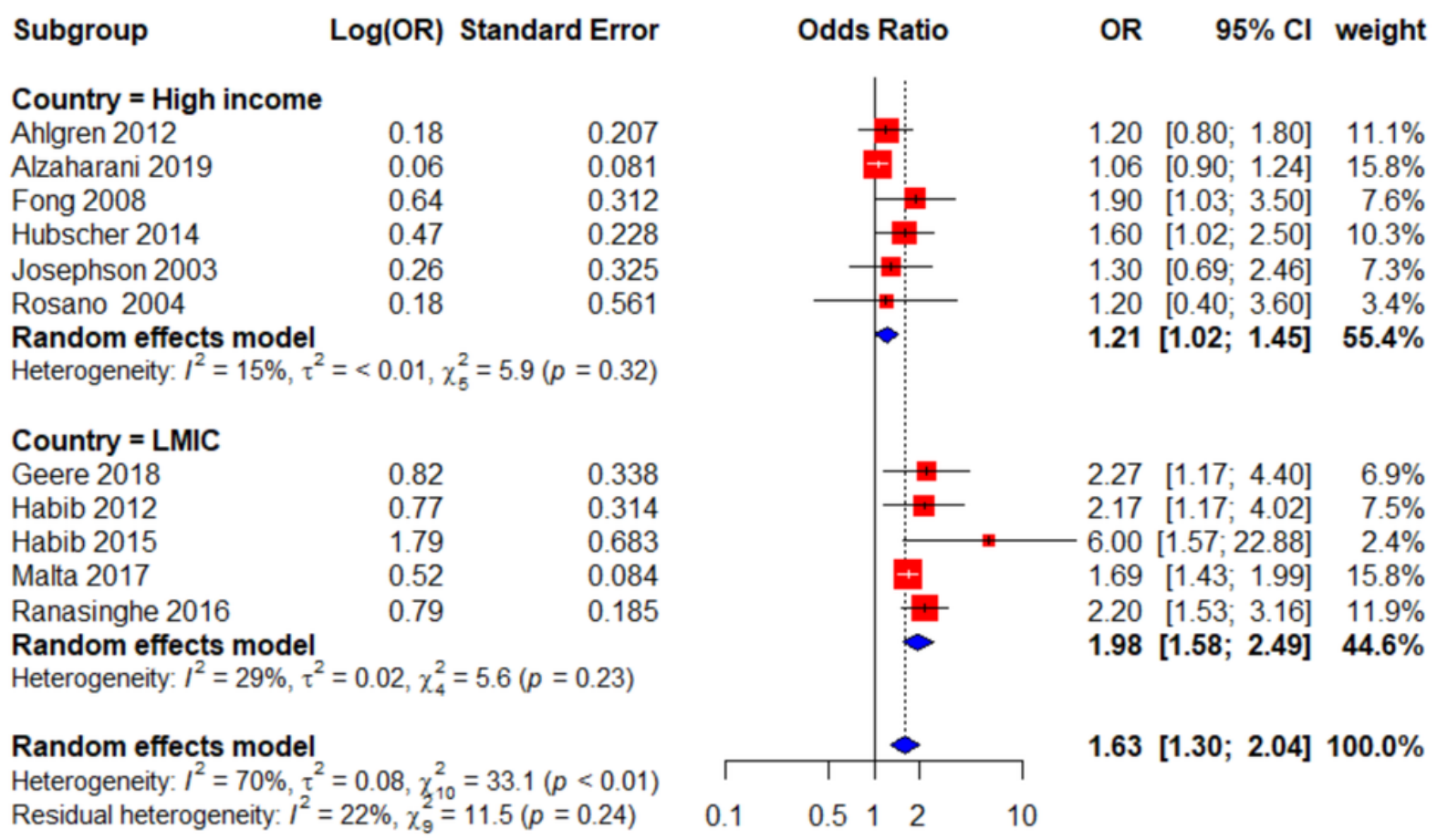

\section{Figure 5}

Forest plot of subgroup analysis based on country status, investigating the association between physically demanding domestic work and back pain in women. Odds ratio (OR); Confidence Interval (Cl). 


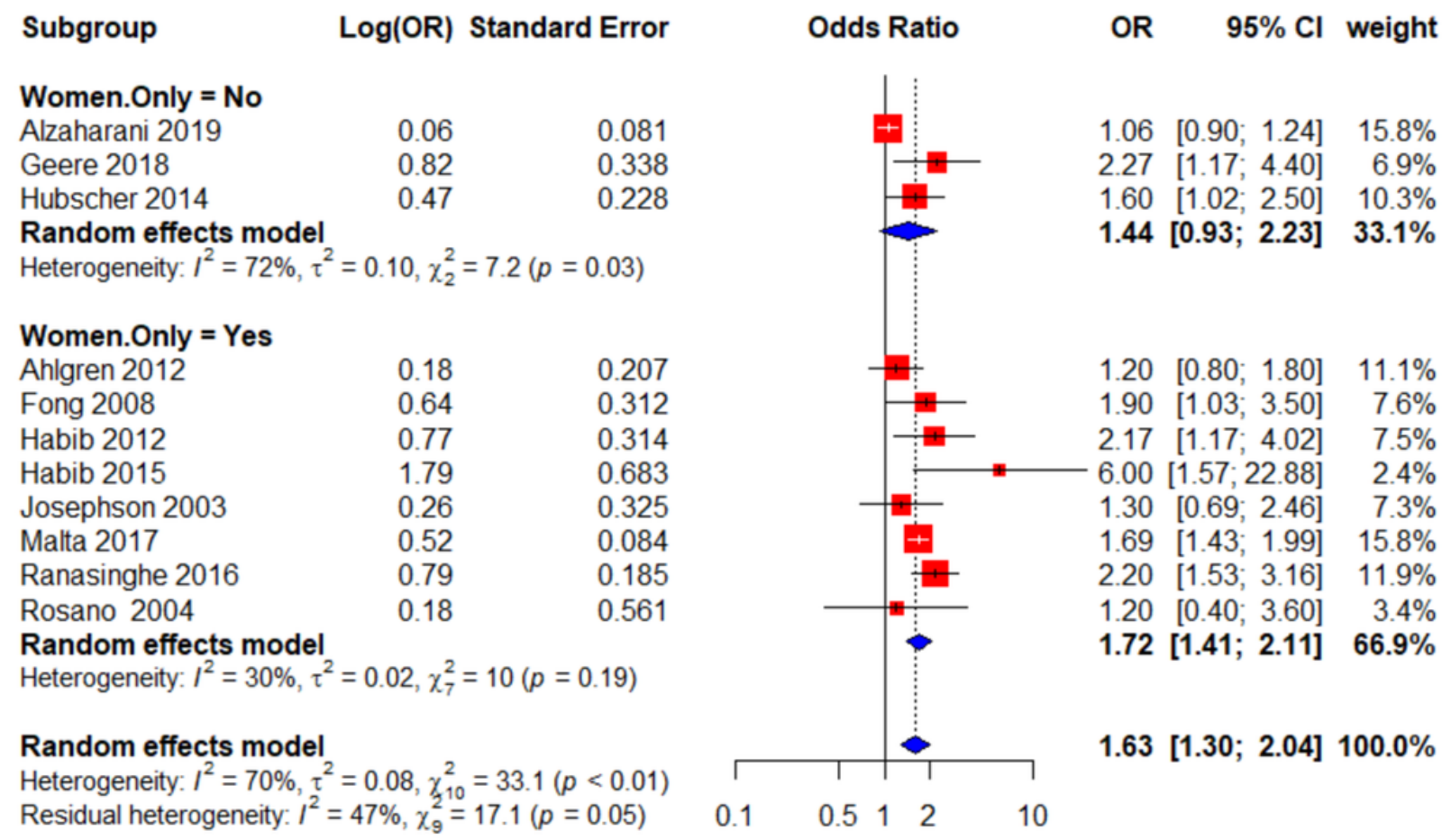

Figure 6

Forest plot of subgroup analysis based on study population, investigating the association between physically demanding domestic work and back pain in women. Odds ratio (OR); Confidence Interval (Cl).

\section{Supplementary Files}

This is a list of supplementary files associated with this preprint. Click to download.

- Otherfileswomenshealth.docx

- PRISMA2009checklistA.O.doc 